\title{
Happiness and Positivity at Workplace in Context of Spirituality: A Conceptual Framework
}

\author{
Aruna Dhamija ${ }^{1}$ \\ ${ }^{1}$ Professor, Institute of Business Management, GLA University, Mathura, India. E-mail: \\ aruna.dhamija@gla.ac.in
}

Article History: Received: 11 January 2021; Accepted: 27 February 2021; Published online: 5 April 2021

\begin{abstract}
Happiness when associate with spirituality in the workplace may be one of the hardest tasks for the employees who have ever witnessed. The potential threat to manage work with happiness in every profession due to competition, expectations and new challenges has engulfed the organizations by now. Employees react differently in their style that depends on how much the individual is spiritual and reflecting happiness at the workplace. This paper attempts to determine the ways to remain happy at the workplace with the help of the Alexander Krolof model. The purpose of this study is to manage the difficult situation and bolster efficiency and effectiveness at the workplace.
\end{abstract}

Keywords: Spirituality, Happiness, Workplace, Alexander Krolof Model.

\section{Introduction}

Human resource have been entered a cutting-edge and unique period in their lives where the world is extremely varying and growing determined out that the happiness while working becomes a challenge. Since the late very last century, within the nineties of the 20th century, a shape of recombination among the inner and outer lifestyles has been forming. Spiritual knowledge collectively with principles, reality, honesty and loyalty may help employees to work under a state of happiness on ethical grounds. To research and commercial enterprise employer and management practices, are all analytical of the emergence of an ultra-current standard (Farhangi, 2006). In modern years, spirituality in businesses is essential for managers, supervisors, personnel and researchers. Need is considered for extractions with companies with personnel, customers and community (Jafardust, 2009). Daniel (2010) suggested that "the idea of spirituality is very important for corporations since businesses can reap profits through the advent of the values of the human surrounding in which employees required to flourish talents".

Happiness creates positive energy and workplace spirituality aimed to be integrating past experiences and build up trust among employees. Therefore, the combination of both will lead to a better and productive environment in the organization. When individuals are happy from inside even has not healthy relationships it does not impact on him. The individual will think in more productive direction, welfare for others, growing with others and with team spirit. Therefore, at workplace an employee full of spirituality is when happy will make the culture of the organization always conducive (Vallabh \& Singhal, 2014).

A few scientists have discovered that the consequence of Workplace Spirituality on well being and bliss has indicated that Workplace Spirituality strongly influences the techniques of lifestyles and bringing down the despondency (Verrier, 2002). Improve Workplace Spirituality in human beings and a team of workers causes that they undergo in thoughts presence with an all-encompassing thing of view, bear in thoughts one in all a kind examples of life, upgrade their correspondence objects and spotlight a robust feeling of a bigger cause in presence that all of them purpose they stable the real which strategies for activities and provide a creative creations weather for them that will motive to extra prominent delight. At the point when people sense cheerful in preference to employment, they can be extra prominent precious for themselves and for pals and the groups which they artwork, due to the reality when the body of workers feel delighted, they will be progressively resourceful and extra noteworthy proficient and can settle on better options and improve their institutions with others.

In the current scenario, next to other elements, first-rate work and feeling of having an area and courting, and association with hierarchical features and strictness are identified with pleasure. Likewise, the consequences of exploration accomplished through Mosallanejad, Badiye Peyma and Mahmoodi, (2013) discovered that there is a terrific connection amongst delight and strictness. Also, the investigations of Yaghoubi and Motahhari (2016) affirmed a lousy pursuing among uneasiness and distress and Spirituality at the Workplace in the understudies of Tehran University. Doolittle and Farrell (2004) expressed during tough times that humans with inordinate Workplace Spirituality stages have lesser despairing levels. These scientists stated that participation at otherworldly abilities does not have masses of effect on human beings' downturn ranges and the issues that recognize solid people from discouraging ones are self-perception in a higher vitality, a petition to this electricity, and dating with it. With the exploration discoveries, couple of proposals is in the affiliation with the current approximately authoritative. 
Workplace Spirituality added materials are given. Thinking approximately the estimation of important innovative creations, making rest bundles for the workforce, conferring conditions beneath which the employees may need to have an inviting reference to their friends, focusing on people's circle of relatives' lives, and presentation of guiding locations for the family are vital. It is moreover viable to work for making the personnel with the usage of project enhancement and vocation improvement programs.

\section{Spirituality in the Workplace}

Spirituality as we apprehend it now is better expertise of self or our inner dimensions, an intrinsic aspect as an individual. It is surprisingly subjective and relates to our deep-seated values and beliefs and which lend to reach out to our motive of life (Sheep, 2006). Often enough it's moreover attention of a Higher power that we renowned and surrenders unconditionally too. That must properly be those factors of our lifestyles that ignite us to undertake the highest purpose and maximizing one, sability.

Ashmos and Duchon (2000) have described spirituality "Understanding and recognizing that employees have an inner life that makes widespread and profitable paintings and reared by the manner of it that this happens in the context of society". Marques, Dhiman and King (2005) states that: Spirituality in the administrative center is revel in a sense of interplay with the people and self-assurance in those who are involved in technical work and is derived of tremendous intentions of humans, which in turn ends inside the collaborative introduction of corporation culture -incentive, that is the super pattern of the relationship and experience of team spirit and results in the overall performance this is rising, ultimately important to the permanent prosperity of an organization.

\section{Happiness}

The term happiness does not mean that to have a road without accidents, a sky without a storm, and work without fatigue and relationships without disappointments. Thornton, (2014) observed that "to remain happy discover to find strength in forgiveness, hope in battles, security in the stage of fear, love in discord, it is not only to enjoy the smile but also to reflect on the sadness". Happiness explains that lessons from failures helps to understand success that which of the attempt one cannot use. That becomes the reason to celebrate and due to which one becomes happy with the appreciation but to be happy in mystery.

It is additionally looked through that happiness isn't to quit feeling like a victim and become your predetermination's creator. It is to cross deserts, yet have the option to discover an oasis in the profundities of your spirit and ought to be grateful to God for the wonder of life.

Being happy is not being afraid of your feelings. It is having the courage to hear a "no". To work at the workplace it builds confidence in the face of criticism, even when unjustified. It is to make compatibility with colleagues, to understand friends, even when they hurt us. As emotion happiness is to let live the individual free, joyful and simple. Happiness can develop a mature relationship with mutual understanding among employees further it creates opportunities for happiness.

Nix, Ryan, Manly and Deci (1999) Khalkhali and Golestane (2011) emphasized that "outline happiness specifically, as a feel of first-rate pleasure that seeks to obtain the desired consequences without interest to incentive mode that prompted those results". Argyle (2001) inside the revel in of happiness described happiness as having three unbiased components-the not unusual stage of pleasure in the route of selected time duration; the frequency and quantity of high wonderful emotions and the relative absence of negative emotion (Moltafet, Mazidi \& Sadati, 2010). Workplace Spirituality brings happiness and being happy with superb thoughts-set will generate sensible and functional outcomes in personal lifestyles and work overall performance. Happiness stimulates person's activity, increases attention, reinforce creativity, authorize social relations, develops supporting participation, and permits to hold his fitness and could grow lifetime (Neshatdoost et al., 2009). In different words, happiness is a superb concept which results in a better work environment invites amongst personnel in a work environment (Bagheri, Akbari \& Hatami, 2011).

Researchers have checked that in the event that human beings utilized in businesses and houses are cheerful and healthy, at that point their general presentation most likely will increment. Numerous years prior, big business nation scientists had situated out that the change of brilliance, temperature, stickiness, and natural commotion straight forwardly influences a person's exhibition. Thusly, it very well may be reasoned that one incredible approach to develop execution at the work environment climate is to apply happy human resources (Yaghoubi and Motahhari, 2016).

Neshatdoost et al. (2009) determined the components impacting bliss among Mobarakeh Steel Company work force. The results affirmed that the faculty bliss is outstandingly identified with their life amuse, positive thinking, family delight, accomplice joy, sports, action fulfillment, celebrating, and insight in god, craftsmanship sports, considering, voyaging, mental issues, and records of substantial sickness. In a research, Olsson et al. (2013) considered satisfaction and pride in drives to work. They said that for some people, satisfaction licenses them to keep up their conventional way of life schedule; all in all, if there are more top notch emotions than the 
terrible ones, individuals can keep up their day by day life. Olsson et al. recommended changing over the work at the work environment in the most basic "Swedish Urban Areas" in their investigations.

\section{Happiness in the Workplace: Alexander Krolof Model}

In a model Alexander Krolof (Hasannejad, Hasannejad and Ghodsi, 2017) focused on how to remain happy at the workplace through six measures included:

\section{a) Thinking Positive}

Employees when working with positivity it becomes powerful thinking to generate outputs with lower inputs (Avey, Reichard, Luthans and Mhatre, 2011). Joy and bliss require thinking amazing and looking for outstanding and magnificent. Thinking worthwhile is considered as one of the important aspects of happiness and become successful in every step of life.

\section{b) Learning}

These days, know-how or knowledge can control and think about capability as it is viewed that this is the vital aid for institutions. The speed of acing in any agency is thought approximately near a little bit of scope. Learning is a strategy in which the practices and mental varieties of people trade, people think and act in any case (Zarei Matin and Akhawan Alavi, 2007). One can adapt profoundly. In this manner, in case you're trying to collect a partnership, this is more agreeable with human instinct and that will fabricate an inner and outer organization (Abbasi and Hejazi, 2011).

\section{c) Self-opening}

Self-opening is itself a self-beginning as it creates satisfaction in the work surroundings and the different way round concealing the actual psyche and sentiments brings about loss of satisfaction and happiness in the spot of business. "Self-reinvention "meaning is to change the way one behaves and other perceives it is an innovative methodology (Caes, 2004). Individuals for the maximum component in early contact with others do no longer show and display the innermost personal feelings.

\section{d) Participation}

The participation in any capacity and at any level at organization is the maximum extremely crucial element for joy. At the component at the same time employee participate in decisions which can be basic for us and we act successfully to construct our future, one will be more blissful. McConvill (2005) observed that participation while decision - making brings confidence and motivation. With that mind set when employees work it automatically creates happiness.

\section{e) Meaningful Work}

Employees while involved at workplace provides better outcome when the work is associated with the overall objective of organization, team, and the society as a whole (Milliman, Czaplewski and Ferguson, 2003). Meaningfulness of work and presence is the maximum large aspect that motivates the widening of the human soul (Chalofsky and Krishna, 2009). The majority of the experts remember the presence of which indicates in methods of lifestyles as the essential factor to constrain people to keep up residing in the latest and presenting a cheerful presence with pride especially.

\section{f) Interests in Work}

Globally love, respect and importance are the greatest first-rate powers and include the universe to work pleasantly at the workplace (Marques, Dhiman, King, 2005). The present gatherings lead humans towards intellectual neediness. To counter this pattern, human beings impart sort of the nearness of fondness in compositions and soul within the workspace. At times display the hypothesis of "nearness of fondness in work" as much as the aspect that even activates ends whole of the nearness of friendship in creative creations causes' additional benefit drives. A happy workplace environment offers the expected legacy to play out these activities in the external world.

The above six additives are possible for every interest and each work environmental elements.

\section{Conclusion}

Working with happiness at workplace with spirituality will discover the way to be happy and to make the work done faultless will further lead to increase the affectivity of the organization Rego, Ribeiro, Cunha and Jesuino, 2011). Hence it will make the employees develop the level of tolerance and develop patience, during mistakes to shape serenity. Moreover, during difficulties will create pleasure and obstacles will remove due to 
spiritual intelligence. This all will develop a never give up attitude that is never give up on happiness as life is an incredible show.

On the off risk that we discover subjects which may be related to greater noteworthy joy, we can acquire pleasure. Workplace Spirituality reasons people emphatically decipher strain and exquisite occasions that seem to them and give them any desire for an advanced method of existence. These human beings regularly display extreme duty during hard circumstances. In highbrow popular, it's far mounted that joyful people revel in extra completely glad exercises within the techniques of life and that those human beings don't forget every single idle occasion as phenomenal. Truth be told, those humans can blast bliss through controlling their contemplations. The people who have extraordinary thoughts and practices they see some aspect clear, the war to accomplishment.

The components of the model grow to be to find out the significance of the connection among the segments of hierarchical Workplace Spirituality and happiness. The significance of these connections transformed is taken into consideration. Barely any investigations have been carried out to offer satisfaction techniques at the spot of employment which make use of authoritative Workplace Spirituality. An examination that is in one manner or another identified with this subject count number is the view through Yaghoubi and Motahhari (2016). Their discoveries confirmed that hierarchical Workplace Spirituality with everything of its measurements can make a stumble upon of pleasure a number of the human beings of an organization.

Considering the elements of the enjoyment of having a place with an association, its miles fundamental to alternate staff's work calendar and application in a manner that leaves them more than one time ultimately of seven days to do their private things. An individual's gift way and position need to be made energizing and energizing and with the guide of preserving happiness packages for the personnel of the tested affiliation, they want to be delivered approximately to enjoy greater happiness in their lives. In the element of the association with boss dreams, offering conditions at the spot of business enterprise beneath which agencies suited borers may be suit for specific their feelings approximately their ingenious creations, pals, or maybe the oversight technique in the partnership have to be considered. Communicating the affiliation's fantasies for its humans want to be thought of. Following this it needs to be noticed that each one the administrations and offices the business assignment has prepared to the humans of the workplace is to assist them with enhancing their lifestyles and that the office thinks about them. At prolonged last, thinking about the estimation of character Workplace Spirituality, preserving strict offerings and growing artwork force' non-commonplace measurement have to moreover be considered.

If the employees are frustrated, dejected, disappointed even without knowing it reflects in different forms such as anger, hurt, jealousy, irritability, irascibility, melancholy, etc. Therapists claim with their past experiences suggest that these emotions in individuals influence one's behavior (Brandt, 2014). Thoughts act as mediators in this process. If the man is the creator of his destiny, then happiness plays an important role at the workplace.

An individual's irrational behaviors may be a result of many adverse experiences in life - however, lack of happiness often catalyzes such reactions. The more you get tangled in the grip of on which one has not controlled the more the individual will find it difficult to extricate himself therefore one should accept the fact and move ahead with positivity.

\section{References}

6. Abbasi, E., \& Hejazi, Y. (2011). The Role of Leadership, Culture and Organizational Learning in Promotion of Iranian Agricultural Faculties' Performance (Establishing Learning Agricultural Faculty). Quarterly Journal of Research and Planning in Higher Education, 16(2), 61-79.

7. Ashmos, D.P., \& Duchon, D. (2000). Spirituality at Work: A Conceptualization and Measure. Journal of Management Inquiry, 9(2), 45-134

8. Avey, J.B., Reichard, R.J., Luthans, F., \& Mhatre, K.H. (2011). Meta-analysis of the impact of positive psychological capital on employee attitudes, behaviors, and performance. Human resource development quarterly, 22(2), 127-152.

9. Bagheri, F., Akbari, F., \& Hatami, H.R. (2011). The Relationship between Happiness and Spiritual Intelligence and Demographic Variables among the Nurses of Fatemeh Alzahra and Bentolhoda Hospitals of the City of Bushehr. Southern Medical Journal, 14(4), 256-263.

10. Brandt, A. (2014). Mindful Anger: A Pathway to Emotional Freedom. WW Norton \& Company.

11. Caes, C.J. (2004). Historical Contingency and Conceptions of the Self in Stalinist and Post-Stalinist Era Polish Literature and Film, 1950-1960. University of California, Berkeley.

12. Chalofsky, N., \& Krishna, V. (2009). Meaningfulness, Commitment, and Engagement: The Intersection of a Deeper Level of Intrinsic Motivation. Advances in Developing Human Resources, 11(2), 189-203.

13. Daniel, J.L. (2010). The Effect of Workplace Spirituality on Team Effectiveness. Journal of Management Development, 29(5), 442-456. 
14. Dhamija, A., Somesh, D., \& Amit, K. (2017). Wisdom of Yoga and Meditation: A Tight Rope to Walk. Purushartha: Journal of School of Management, Ethics and Spirituality, 10(1), 117-125. https://doi.org/10.21844/pajmes.v10i1.7802.

15. Dhamija, A., Somesh, D., \& Krishanveer, S. (2019). Mediation Effect of Passion between Intimacy and Commitment in Relationship with God: Triangular Theory of Love. Purushartha: Journal of School of Management, Ethics and Spirituality, 11(2), 1-13. https://doi.org/10.21844/pajmes.v11i2.14624.

16. Doolittle, B.R., \& Farrell, M. (2004). The Association between Spirituality and Depression in an Urban Clinic. Primary Care Companion to the Journal of Clinical Psychiatry, 6(3), 114.

17. Farhangi, A. (2006). Spirituality in the Workplace and its role in Improving Organizational Citizenship Behavior. Management Culture: Persian journal.

18. Hasannejad, Z., Hasannejad, A.H., \& Ghodsi, E. (2017). Investigating the Relation of Spirituality in the Workplace with Happiness of Employees. International Journal of Scientific Study, 5(3), 147-153.

19. Jafardust, M. (2009). The Place of Spirituality in Organization Theory, Management, seventeenth year, Issue 40.

20. Khalkhali, V., \& Golestaneh, S.M. (2011). Examining the Impact of Teacher Motivational Style and Competition Result on Students' Subjective Vitality and Happiness in Physical Education. ProcediaSocial and Behavioral Sciences, 15, 2989-2995.

21. Marques, J., Dhiman, S., \& King, R. (2005). Spirituality in the Workplace: Developing an Integral Model and a Comprehensive Definition. Journal of American Academy of Business, 7(1), 81-91.

22. McConvill, J. (2005). Piercing the Decision-Making Sphere: Happiness as the Key to Real Shareholder Participation. Eur. Bus. L. Rev., 16, 831.

23. Milliman, J., Czaplewski, A.J., \& Ferguson, J. (2003). Workplace spirituality and employee work attitudes: An exploratory empirical assessment. Journal of organizational change management, 16(4), 426-447.

24. Moltafet, G., Mazidi, M., \& Sadati, S. (2010). Personality traits, religious orientation and happiness. Procedia-Social and Behavioral Sciences, 9, 63-69.

25. Mosallanejad, L., Badiye Peyma, Z., \& Mahmoodi, Y. (2013). The association between religious attitude and optimism in students of nursing and Paramedicine faculty of Jahrom University. Islam Life Center Health, 1(4), e13914.

26. Neshatdoost, H.T. (2009). Determination the Factors Influencing Employees' Happiness. Journal of Applied Sociology, 20(1), 33.

27. Nix, G.A., Ryan, R.M., Manly, J.B., \& Deci, E.L. (1999). Revitalization through self-regulation: The effects of autonomous and controlled motivation on happiness and vitality. Journal of experimental social psychology, 35(3), 266-284.

28. Olsson, L.E., Gärling, T., Ettema, D., Friman, M., \& Fujii, S. (2013). Happiness and satisfaction with work commute. Social indicators research, 111(1), 255-263.

29. Rego, A., Ribeiro, N., e Cunha, M.P., \& Jesuino, J.C. (2011). How happiness mediates the organizational virtuousness and affective commitment relationship. Journal of Business Research, 64(5), 524-532.

30. Sheep, M.L. (2006). Nurturing the whole person: The ethics of workplace spirituality in a society of organizations. Journal of business ethics, 66(4), 357-375.

31. Thornton, L. (2014). Through Heaven's Gate and Back: A Spiritual Journey of Healing and What it Taught Me About Love, Life, and Forgiveness. Lulu. com.

32. Vallabh, P., \& Singhal, M. (2014). Workplace spirituality facilitation: A person-organization fit approach. Journal of human values, 20(2), 193-207.

33. Verrier, D.R. (2002). Spiritual fulfilment in a utility company of the City of Johannesburg: A phenomenological study (Doctoral dissertation, University of Johannesburg).

34. Yaghoubi, N.M., \& Motahhari, Z. (2016). Happiness in the light of organizational spirituality: Comprehensive approach. International Journal of Organizational Leadership, 5, 123-136.

35. Zarei Matin, H., \& Akhawan Alavi, S. H. (2007). Identifying the barriers of developing organizational learning in administrative organizations. Iranian Journal of Management Studies, 1(1), 17-38. 